\title{
Iron and nitrogen self-diffusion in non-magnetic iron nitrides
}

\author{
Mukul Gupta, ${ }^{1, a)}$ Akhil Tayal, Ajay Gupta, ${ }^{1}$ Rachana Gupta, ${ }^{2}$ J. Stahn, ${ }^{3}$ \\ M. Horisberger, ${ }^{4}$ and A. Wildes ${ }^{5}$ \\ ${ }^{1}$ UGC-DAE Consortium for Scientific Research, University Campus, Khandwa Road, Indore-452 001, India \\ ${ }^{2}$ Institute of Engineering and Technology, Khandwa Road, Devi Ahilya Vishwavidyalaya, Indore 452017, \\ India \\ ${ }^{3}$ Laboratory for Neutron Scattering, Paul Scherrer Institut, CH-5232 Villigen PSI, Switzerland \\ ${ }^{4}$ Laboratory for Developments and Methods, Paul Scherrer Institut, CH-5232 Villigen PSI, Switzerland \\ ${ }^{5}$ Institut Laue-Langevin, rue des Martyrs, 38042 Grenoble Cedex, France
}

(Received 2 May 2011; accepted 18 November 2011; published online 23 December 2011)

\begin{abstract}
The self-diffusion of iron and nitrogen is measured in $\mathrm{nm}$ range non-magnetic iron nitride thin films. Two non-magnetic iron nitrides, $\mathrm{Fe}_{2.23} \mathrm{~N}$ and $\mathrm{FeN}$, were studied using neutron reflectivity. Neutron reflectivity with a depth resolution in the sub-nm range has a different scattering cross section for isotopes, providing a unique opportunity to measure very small diffusivities. The isotope heterostructure in thin film multilayers $\left[\mathrm{Fe}-\mathrm{N} /{ }^{57} \mathrm{Fe}-\mathrm{N}\right]_{10}$ and $\left[\mathrm{Fe}-\mathrm{N} / \mathrm{Fe}-{ }^{15} \mathrm{~N}\right]_{10}$ were prepared using magnetron sputtering. It was observed that nitrogen diffuses slower than iron although the atomic size of iron is larger than that of nitrogen. It was found that a significantly larger group of $\mathrm{N}$ atoms participates in the diffusion process than of $\mathrm{Fe}$, making $\mathrm{N}$ diffusion slower than that of Fe. (C) 2011 American Institute of Physics. [doi:10.1063/1.3671532]
\end{abstract}

\section{INTRODUCTION}

Iron nitrides (Fe-N) show a variety of structures and magnetic properties with variation in the nitrogen content. With an increasing atomic percentage (at. \%) of $\mathrm{N}$, the major phases are $\mathrm{Fe}_{16} \mathrm{~N}_{2}, \mathrm{Fe}_{4} \mathrm{~N}, \mathrm{Fe}_{3} \mathrm{~N}, \mathrm{Fe}_{2} \mathrm{~N}, \mathrm{FeN}$, and $\mathrm{Fe}_{3} \mathrm{~N}_{4}$. With $\leq 25$ at. $\% \mathrm{~N}$, the $\mathrm{Fe}-\mathrm{N}$ phases are magnetic. ${ }^{1} \mathrm{~A}$ lot of attention has been devoted to $\alpha^{\prime \prime}-\mathrm{Fe}_{16} \mathrm{~N}_{2}(\sim 11$ at. $\% \mathrm{~N})$ due to the presence of the so-called giant magnetic moment in this compound. $^{2,3}$ Around 20 at. $\% \mathrm{~N}$, the $\gamma^{\prime}-\mathrm{Fe}_{4} \mathrm{~N}$ phase is formed, which has well-defined magnetic properties and crystal structure. ${ }^{4}$ The $\gamma^{\prime}-\mathrm{Fe}_{4} \mathrm{~N}$ phase has received a lot of interest due to its chemical inertness and mechanically hard surfaces, which make it a suitable alternative to pure $\mathrm{Fe}$ in magnetic devices. ${ }^{4-8}$ Between 25 and 33 at. $\%$ N, the Fe-N are known as $\epsilon-\mathrm{Fe}_{x} \mathrm{~N}(2 \leq x \leq 3)$, and as the $\mathrm{N}$ at. $\%$ increases from 25 to 33 , the phase changes from ferromagnetic $\mathrm{Fe}_{3} \mathrm{~N}$ to paramagnetic $\mathrm{Fe}_{2} \mathrm{~N}$ at room temperature.

Using conventional methods, e.g., the evaporation of iron in the presence of nitrogen or ammonia, it was not possible to produce non-magnetic $\mathrm{Fe}-\mathrm{N}$. But by using reactive sputtering, ${ }^{9-19}$ pulsed laser deposition techniques, ${ }^{20}$ and the evaporation of $\mathrm{Fe}$ in a flux of atomic nitrogen plasma, ${ }^{6,21}$ nonmagnetic Fe-N having about 50 at. $\% \mathrm{~N}$ were prepared in the form of thin films only. This FeN phase can appear in two possible fcc crystalline structures: a ZnS-type and a $\mathrm{NaCl}$ type structure. Theoretical calculations have been carried out for these compounds ${ }^{22-25}$ and indicate that the NaCl-type phase is not stable. Recently it was concluded that $\mathrm{FeN}$ with a lattice constant of $0.43 \mathrm{~nm}$ is $\gamma^{\prime \prime}-\mathrm{FeN}^{6}$, and that with a lattice constant of $0.45 \mathrm{~nm}$ is $\gamma^{\prime \prime \prime}-\mathrm{FeN}{ }^{19}$ In addition, an $\mathrm{Fe}_{3} \mathrm{~N}_{4}$ phase

\footnotetext{
a) Author to whom correspondence should be addressed. Electronic mail: mgupta@csr.res.in.
}

with even more than 50 at. \% $\mathrm{N}$ was predicted by Ching et al. ${ }^{26}$ but has not yet been evidenced experimentally.

Concerning the applications of iron nitrides, the magnetic iron nitrides $(\mathrm{N}$ at. $\%<25)$ are well known due to their chemical inertness and mechanically hard surfaces. ${ }^{27}$ This, together with their intrinsic magnetic properties, makes them a suitable material as an alternative to pure $\mathrm{Fe}$ in devices such as reading heads for magnetic storage devices. ${ }^{28}$ Only recently non-magnetic iron mononitrides have emerged as a promising material in spintronics applications. ${ }^{5-7}$ Controlled annealing of $\mathrm{FeN}$ produces the $\gamma^{\prime}-\mathrm{Fe}_{4} \mathrm{~N}$ phase and thus provides a source of spin injection for semiconductors or diluted magnetic semiconductors. ${ }^{24}$

In the present work, we have prepared single phase (polycrystalline) $\epsilon-\mathrm{Fe}_{2} \mathrm{~N}$ and $\gamma^{\prime \prime \prime}-\mathrm{FeN}$ compounds using magnetron sputtering. The chemical and magnetic structures of the samples were obtained using x-ray diffraction and conversion electron Mössbauer spectroscopy. The self-diffusion of $\mathrm{Fe}$ and $\mathrm{N}$ was studied using neutron reflectivity, and the obtained results were confirmed using the secondary ion mass spectroscopy technique. A proper understanding of the stability and nitride formation requires knowledge of both $\mathrm{Fe}$ and $\mathrm{N}$ self-diffusion at atomic length scales. Although the diffusion processes in magnetic bcc-iron nitrides have been discussed, ${ }^{21,29,30}$ the diffusion coefficients for Fe and $\mathrm{N}$ selfdiffusion in nonmagnetic $\mathrm{Fe}-\mathrm{N}$ have not been quantified. Conventional techniques for measuring self-diffusion (e.g., secondary ion mass spectroscopy, radioactive tracers, etc.) have depth resolutions of several $\mathrm{nm}$. Therefore, in order to measure diffusion at a nanometer length scale, a technique with depth resolution in the sub-nm regime is necessary. ${ }^{31}$ Here, the method of choice is neutron reflectometry (NR), which in addition is sensitive to isotopic contrast. The neutron scattering lengths for natural $\mathrm{Fe}$ and ${ }^{57} \mathrm{Fe}$ are 9.45 
and $2.3 \mathrm{fm}$, and for natural $\mathrm{N}$ and ${ }^{15} \mathrm{~N}$ they are 9.36 and 6.6 fm, respectively.

\section{EXPERIMENTAL}

The samples studied in this work were prepared via reactive dc magnetron sputtering at a power of $50 \mathrm{~W}$ at room temperature (without intentional heating). The actual thicknesses (obtained via the fitting of neutron reflectivity data) of the samples are as follows:

Sample $A 1$ : $\left[\mathrm{Fe}-\mathrm{N}(7.5 \mathrm{~nm}) /{ }^{57} \mathrm{Fe}-\mathrm{N}(4.5 \mathrm{~nm})\right]_{10}$ Sample $A 2:\left[\mathrm{Fe}-\mathrm{N}(6.4 \mathrm{~nm}) / \mathrm{Fe}-{ }^{15} \mathrm{~N}(3.2 \mathrm{~nm})\right]_{10}$ Sample $B 1$ : $\left[\mathrm{Fe}-\mathrm{N}(10.2 \mathrm{~nm}) /{ }^{57} \mathrm{Fe}-\mathrm{N}(5.2 \mathrm{~nm})\right]_{10}$ Sample $B 2$ : $\left[\mathrm{Fe}-\mathrm{N}(10.6 \mathrm{~nm}) / \mathrm{Fe}-{ }^{15} \mathrm{~N}(5.2 \mathrm{~nm})\right]_{10}$

Prior to the deposition of the samples, a base pressure of about $1 \times 10^{-7}$ mbar was achieved. Samples $A 1$ and $A 2$ were prepared using $\left(\mathrm{N}_{2}+\mathrm{Ar}\right)$ gases, each at $5 \mathrm{SCCM}$ (50\% nitrogen), and samples $B 1$ and $B 2$ were prepared using $10 \mathrm{SCCM}$ $\mathrm{N}_{2}$ (100\% nitrogen) as the sputter gas (SCCM denotes cubic centimeters per minute at standard temperature and pressure). The pressure during the deposition was about $1 \times 10^{-3}$ mbar. More details about the sample preparation are given in Ref. 18. The multilayer with ${ }^{57} \mathrm{Fe}$ was deposited by alternately sputtering $\mathrm{Fe}$ and ${ }^{57} \mathrm{Fe}$ enriched targets, and the ${ }^{15} \mathrm{~N}$ multilayer was prepared using the same $\mathrm{Fe}$ target but switching between $\mathrm{N}_{2}$ and ${ }^{15} \mathrm{~N}_{2}$ gases. A residual gas analyzer was installed in the sputtering chamber to monitor the isotope abundance of nitrogen. For preparation of the $\mathrm{Fe}^{-15} \mathrm{~N}$ layer, before introducing ${ }^{15} \mathrm{~N}_{2}$ gas into the chamber, the chamber was pumped until the partial pressure of natural nitrogen gas was reduced to background pressure. Similarly, for preparation of the Fe-N layer, the partial pressure of ${ }^{15} \mathrm{~N}_{2}$ gas was reduced to background pressure. This exercise was repeated at each layer in order to remove contamination of ${ }^{15} \mathrm{~N}$ in the $\mathrm{Fe}-\mathrm{N}$ layer, and vice versa.

The samples were characterized using $\mathrm{X}$-ray reflectivity and $\mathrm{x}$-ray diffraction (XRD) using $\mathrm{Cu}-\mathrm{K} \alpha \mathrm{x}$-rays. The XRD measurements were carried out in the grazing incidence mode, keeping the incoming $x$-rays at an angle of $1^{\circ}$. The thermal stability of the samples was examined using differential scanning calorimetry (DSC). The conversion electron Mössbauer spectroscopy (CEMS) measurements were carried out at room temperature using a ${ }^{57} \mathrm{Co}$ source embedded in a rhodium matrix and calibrated to the hyperfine field of ${ }^{57} \mathrm{Fe}$. The conversion electrons were detected by a proportional counter with a continuous flow of a helium-methane (5\% methane balance helium) gas mixture. The NR measurements were performed at the reflectometers AMOR (for samples $A 1$ and $A 2)$ at SINQ (Paul Scherrer Institut) (Ref. 32) and D17 at Institut Laue-Langevin (Ref. 33) (for samples $B 1$ and $B 2$ ), both operating in the time-of-flight mode.

\section{RESULTS AND DISCUSSION}

The XRD pattern of samples $A 1$ and $A 2$ (Fig. 1(b)) shows peaks corresponding to $\epsilon-\mathrm{Fe}_{x} \mathrm{~N}$ with a hexagonal close packed structure. The CEMS spectrum of this sample (Fig. 1(a)) shows an asymmetric doublet that was fitted using two doublets corresponding to Fe-III and Fe-II sites (shown as
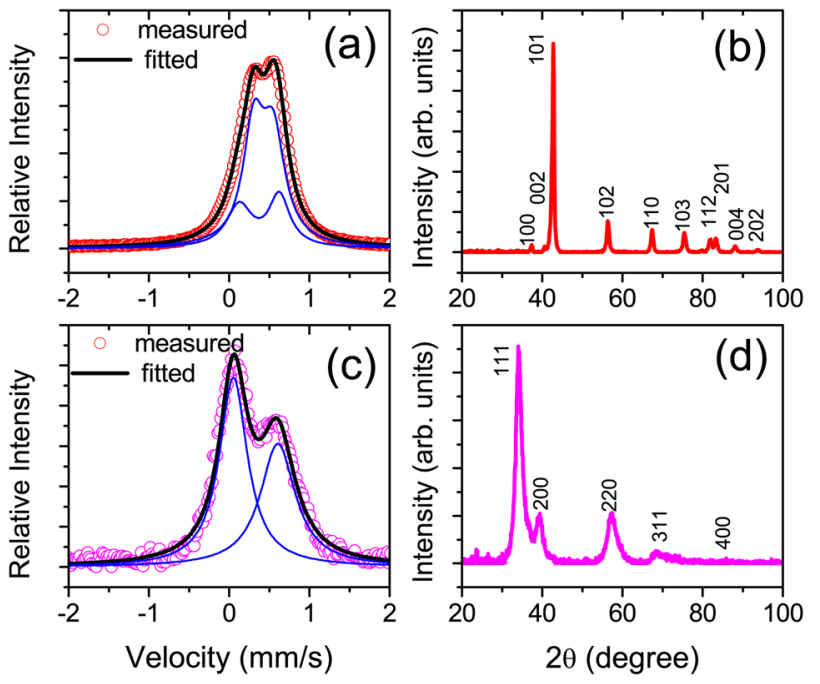

FIG. 1. (Color online) The conversion electron Mössbauer spectroscopy spectra of samples $A 1$ and $A 2$ (a) and samples $B 1$ and $B 2$ (c), and the XRD pattern of samples $A 1$ and $A 2$ (b) and samples $B 1$ and $B 2$ (d).

thin lines in Fig. 1(a)) with isomer shifts of $0.43 \pm 0.002$ and $0.37 \pm 0.002 \mathrm{~mm} / \mathrm{s}$, quadrupole splitting of $0.24 \pm 0.002$ and $0.50 \pm 0.004 \mathrm{~mm} / \mathrm{s}$, and a relative area ratio of 69:31. The fitted parameters match well with the reported values, and using the relative area ratio we obtain a value of $x=2.23$ following the procedure given in Ref. 12 . This gives the composition of samples $A 1$ and $A 2$ as $\epsilon-\mathrm{Fe}_{2.23} \mathrm{~N}$.

The XRD pattern of samples $B 1$ and $B 2$ (Fig. 1(d)) shows all the peaks corresponding to the $\gamma^{\prime \prime \prime}$-FeN phase with a lattice parameter $a=0.454 \pm 0.001 \mathrm{~nm}$. The CEMS pattern (Fig. 1(c)) shows an asymmetric doublet and was fitted using two singlets (shown as thin lines in Fig. 1(c)) with isomer shifts of $0.05 \pm 0.002$ and $0.6 \pm 0.003 \mathrm{~mm} / \mathrm{s}$. The XRD and CEMS parameters match well with the values obtained by Jouanny et al. ${ }^{19}$ This gives the composition of samples $B 1$ and $B 2$ as $\gamma^{\prime \prime \prime}$-FeN with a ZnS-type structure with $\approx 50$ at. $\% \mathrm{~N}$. This structure was also confirmed with low temperature and high field Mössbauer spectroscopy measurements. ${ }^{34}$ As can be seen from Figs. 1(b) and 1(d), the peak widths corresponding to samples $B 1$ and $B 2$ are broader than those in samples $A 1$ and $A 2$. This indicates that the average grain sizes in samples $B 1$ and $B 2$ are significantly larger than those in samples $A 1$ and $A 2$. The average grain size was calculated using the Scherrer formula, $t=0.9 \lambda / \Delta q \cos \theta$, where $t$ is the grain size, $\Delta q$ is the angular width of the reflection, $\theta$ is the Bragg angle, and $\lambda$ is the wavelength of the radiation $(=1.54 \AA$ ). The obtained values of the grain size for the most intense peak for the $A 1 / A 2$ and $B 1 / B 2$ samples are $16 \mathrm{~nm}$ and $5 \mathrm{~nm}$, respectively.

The thermal stability of the samples was studied using XRD and DSC. In the temperature range of 373-573 K, there was no appreciable change in the XRD patterns. The DSC measurements showed a strong exothermic peak at $650 \mathrm{~K}$, indicating out-diffusion of nitrogen, as observed in an earlier study. ${ }^{15}$ Therefore, $523 \mathrm{~K}$ was chosen as the maximum annealing temperature for the diffusion measurements.

The ${ }^{57} \mathrm{Fe}$ and ${ }^{15} \mathrm{~N}$ periodicity in the multilayers gives rise to Bragg peaks in the NR pattern, as shown in Fig. 2 $(A 1, B 1)$ for ${ }^{57} \mathrm{Fe}$ contrast and in Fig. $2(A 2, B 2)$ for ${ }^{15} \mathrm{~N}$ 


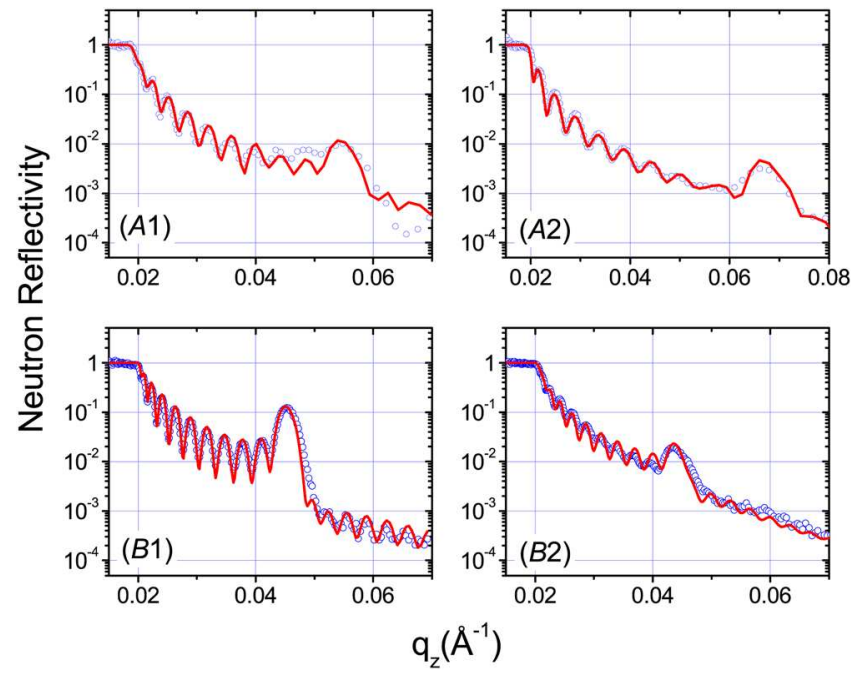

FIG. 2. (Color online) Neutron reflectivity pattern of as prepared isotope multilayer samples $\left[\epsilon-\mathrm{Fe}_{2.23} \mathrm{~N}(7.5 \mathrm{~nm}) / \epsilon-{ }^{57} \mathrm{Fe}_{2.23} \mathrm{~N}(4.5 \mathrm{~nm})\right]_{10}(A 1),\left[\epsilon-\mathrm{Fe}_{2.23} \mathrm{~N}(6.4\right.$ $\left.\mathrm{nm}) / \epsilon-\mathrm{Fe}_{2.23}{ }^{15} \mathrm{~N}(3.2 \mathrm{~nm})\right]_{10}(A 2),\left[\gamma^{\prime \prime \prime}-\mathrm{FeN}(10.2 \mathrm{~nm}) / \gamma^{\prime \prime \prime}{ }_{-}^{57} \mathrm{FeN}(5.2 \mathrm{~nm})\right]_{10}$ $(B 1)$, and $\left[\gamma^{\prime \prime \prime}-\mathrm{FeN}(10.6 \mathrm{~nm}) / \gamma^{\prime \prime \prime}-\mathrm{Fe}^{15} \mathrm{~N}(5.2 \mathrm{~nm})\right]_{10}(\mathrm{~B} 2)$.

contrast. The total thickness oscillations, also known as Kiessig fringes, appear due to the reflection from the air-film and film-substrate interfaces and correspond to the total thickness of the multilayer. The NR pattern was fitted using a computer program ${ }^{35}$ based on Parratt's formulism. ${ }^{36}$ The typical values of the surface and interface roughness were about $1 \mathrm{~nm}$. In order to check the chemical homogeneity of the samples, we performed x-ray reflectivity measurements (not shown), and they revealed a pattern corresponding to a single layer, as expected, due to the absence of contrast between isotope layers for $\mathrm{x}$-rays.

The samples were annealed at various annealing temperatures in a vacuum furnace for different annealing times. The furnace was installed at the sample position of neutron reflectometers. Thermal annealing of the samples led to a decay of the Bragg peak in the NR pattern. Some representative NR patterns for samples $A 1$ and $A 2$ at annealing temperature of $373 \mathrm{~K}$ for different annealing times are shown in Fig. 3; panels $(A 1)$ and $(A 2)$ correspond to Fe and $\mathrm{N}$ contrast, respectively. Similarly, plots for samples $B 1$ and $B 2$ at an annealing temperature of $463 \mathrm{~K}$ for different annealing times are shown in Fig. 3; panels $(B 1)$ and $(B 2)$ represent Fe and $\mathrm{N}$ contrast, respectively. The NR pattern was multiplied by $\mathrm{q}_{\mathrm{z}}{ }^{4}$ (where $\mathrm{q}_{\mathrm{z}}$ is the momentum transfer vector normal to the surface and is given by $\mathrm{q}_{\mathrm{z}}=4 \pi \sin \theta / \lambda$, with $\theta$ being the angle of incidence and $\lambda$ being the wavelength of neutrons) in order to remove the decay due to Fresnel's reflectivity. In Fig. 3 it is interesting to observe that the total thickness oscillations between the critical edge and the first order Bragg peak can be seen even after the highest annealing time. Therefore the presence of total thickness oscillations even after annealing of the samples indicates that the surface and the interface of the sample with the substrate remain sharp.

The decay of the Bragg peak with thermal annealing is due to $\mathrm{Fe}$ or $\mathrm{N}$ diffusion across ${ }^{57} \mathrm{FeN} / \mathrm{FeN}$ and $\mathrm{FeN} / \mathrm{Fe}^{15} \mathrm{~N}$ interfaces. The decay of the Bragg peak intensity can be used to calculate the instantaneous diffusivity $\left(D_{i}\right)$ using the expression $^{38,39}$

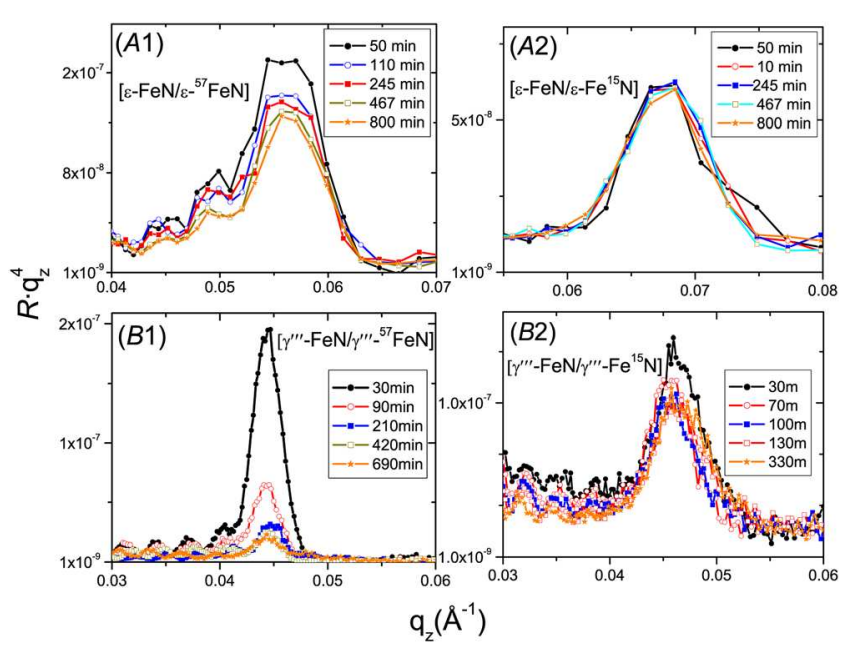

FIG. 3. (Color online) Representative neutron reflectivity pattern (reflectivity $R$, multiplied by $\mathrm{q}_{\mathrm{z}}{ }^{4}$ for better visualization of the Bragg peak) of samples $A 1$ and $A 2$ measured at $373 \mathrm{~K}$ and of samples $B 1$ and $B 2$ measured at $463 \mathrm{~K}$ for different annealing times.

$$
\ln [I(t) / I(0)]=-8 \pi^{2} D_{i} t / d^{2},
$$

where $I(0)$ is the intensity of the first order Bragg peak at time $t=0$ (before annealing) and $d$ is the bilayer thickness. Such decay of the Bragg peak with thermal annealing has been used to measure self-diffusion in a number of multilayer systems, e.g., $\mathrm{FeZr} /{ }^{57} \mathrm{FeZr},{ }^{31} \mathrm{Ni} /{ }^{62} \mathrm{Ni},{ }^{39} \mathrm{FePt} /{ }^{57} \mathrm{FePt},{ }^{40}$ $\mathrm{Si}_{3} \mathrm{~N}_{4} / \mathrm{Si}_{3}{ }^{15} \mathrm{~N}_{4}{ }^{41}$ etc.

A plot of instantaneous diffusivities obtained using Eq. (1) for the data shown in Fig. 3 is shown in Fig. 4. As the structure tends to relax, the time averaged diffusivity is defined as ${ }^{37}$

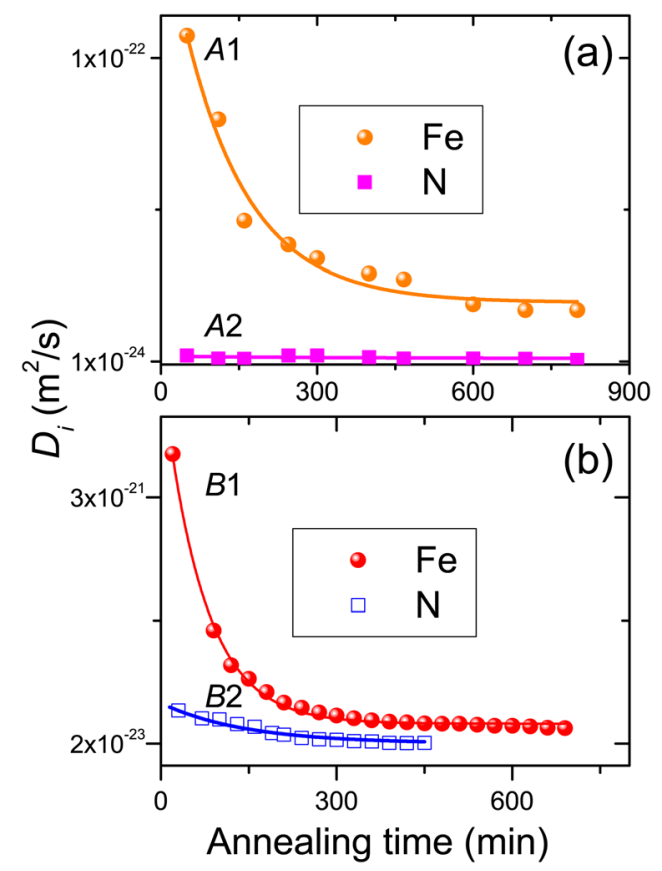

FIG. 4. (Color online) Time dependence of Fe and N instantaneous diffusivity for samples $A 1$ and $A 2$ at $373 \mathrm{~K}$ (a) and for samples $B 1$ and $B 2$ at $463 \mathrm{~K}$ (b). The scattered points correspond to measured data, and the solid lines correspond to the fit obtained using Eq. (3). 

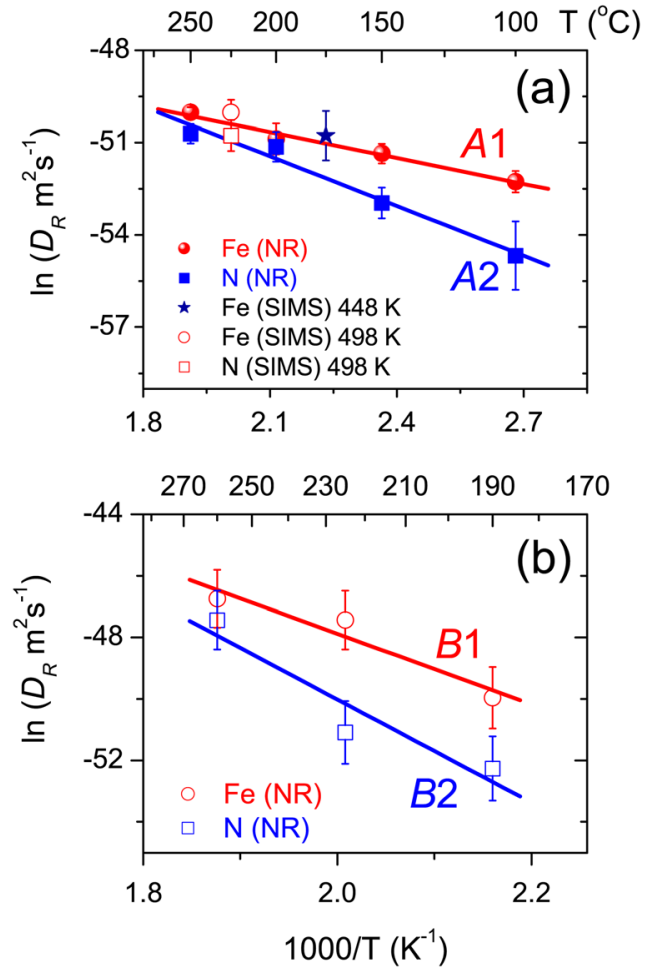

FIG. 5. (Color online) Arrhenius behavior of Fe and $\mathrm{N}$ diffusivity for samples $A 1$ and $A 2$ (a) and for samples $B 1$ and $B 2$ (b). The scattered points correspond to measured data, and the solid lines correspond to the fit obtained using $D_{R}=D_{0} \exp \left(-E / k_{\mathrm{B}} T\right)$, where $D_{R}$ is the diffusivity in the relaxed state, $D_{0}$ is a pre-exponential factor, $E$ is the activation energy, $k_{\mathrm{B}}$ is Boltzmann's constant, and $T$ is the annealing temperature.

$$
\bar{D}=\frac{1}{t} \int_{0}^{t} D_{i}\left(t^{\prime}\right) d t^{\prime}
$$

Assuming an exponential law for the relaxation,

$$
D_{i}(t)=\text { Const. } \exp (-t / \tau)+D_{R},
$$

where $D_{R}$ is the diffusivity in the relaxed state and $\tau$ is the relaxation time. By using Eq. (3), the diffusivities in the structurally relaxed state were obtained. The temperature dependence of the diffusivity obtained in the structurally relaxed state follows an Arrhenius-type behavior as shown in Fig. 5(a) for samples $A 1$ and $A 2$. Similarly, for samples $B 1$ and $B 2$, the Arrhenius behavior for $\mathrm{Fe}$ and $\mathrm{N}$ diffusivity is shown in Fig. 5(b). The straight line fit to the data was obtained using $D_{R}=D_{0} \exp \left(-E / k_{\mathrm{B}} T\right)$, with $k_{\mathrm{B}}$ being Boltzmann's constant. This yields the pre-exponential factor $D_{0}$ and activation energy $E$, which are given in Table I. The

TABLE I. Parameters for Fe-N samples.

\begin{tabular}{lcccc}
\hline \hline Sample & $A 1$ & $A 2$ & $B 1$ & $B 2$ \\
\hline$E_{\mathrm{Fe}}(\mathrm{eV})$ & $0.25 \pm 0.03$ & $\ldots$ & $1.0 \pm 0.2$ & $\ldots$ \\
$E_{\mathrm{N}}(\mathrm{eV})$ & $\ldots$ & $0.46 \pm 0.08$ & $\ldots$ & $1.5 \pm 0.3$ \\
$\ln D_{0 \mathrm{Fe}}\left(\mathrm{m}^{2} / \mathrm{s}\right)$ & $-44 \pm 1$ & $\ldots$ & $-25 \pm 10$ & $\ldots$ \\
$\ln D_{0 \mathrm{~N}}\left(\mathrm{~m}^{2} / \mathrm{s}\right)$ & $\ldots$ & $-41 \pm 2$ & $\ldots$ & $-16 \pm 10$ \\
$\Delta S_{\mathrm{Fe}}\left(k_{\mathrm{B}}\right)$ & 5 & $\ldots$ & 9 & $\ldots$ \\
$\Delta S_{\mathrm{N}}\left(k_{\mathrm{B}}\right)$ & $\ldots$ & 19 & $\ldots$ & 28 \\
\hline \hline
\end{tabular}

comparison of $\mathrm{Fe}$ and $\mathrm{N}$ diffusivity among all samples reveals that the values of $E$ are greater in samples $B 1$ and $B 2$ than in samples $A 1$ and $A 2$. This indicates a slower diffusion of Fe and $\mathrm{N}$ in samples $B 1$ and $B 2$.

Regarding the enthalpies of formation $\left(\Delta H^{\circ}\right)$, the values for $\mathrm{FeN}$ are lower than those for $\mathrm{Fe}_{2} \mathrm{~N}$ or other $\mathrm{Fe}-\mathrm{N}$ phases. ${ }^{42}$ This means that $\mathrm{FeN}$ is expected to be more stable than $\mathrm{Fe}_{2} \mathrm{~N}$, and therefore $E$ for $\mathrm{Fe}$ and $\mathrm{N}$ self-diffusion should be higher in $\mathrm{FeN}$ than in $\mathrm{Fe}_{2} \mathrm{~N}$. Though the differences in the obtained values of diffusivity in both samples can be understood in terms of the energetics of iron nitrides, the difference between the $\mathrm{Fe}$ and $\mathrm{N}$ self-diffusion is counterintuitive, as the atomic size of $\mathrm{Fe}\left(r_{\mathrm{Fe}}=0.1274 \mathrm{~nm}\right)$ is larger than that of $\mathrm{N}\left(r_{\mathrm{Fe}} / r_{\mathrm{N}}\right.$ $\approx 1.6$ ). Therefore, it is expected that $\mathrm{N}$ should diffuse faster than $\mathrm{Fe}$, as observed in a N-poor magnetic Fe-N. ${ }^{30}$

In order to further confirm this behavior, we carried out secondary ion mass spectroscopy (SIMS) measurements in a sample prepared with a marker layer of $\epsilon-{ }^{57} \mathrm{Fe}_{2.23}{ }^{15} \mathrm{~N}$. This marker layer was sandwiched between natural $\epsilon-\mathrm{Fe}_{2.23} \mathrm{~N}$ layers. The structure of the sample prepared for SIMS measurements was $\mathrm{Si}$ (substrate) $/ \epsilon$ $\mathrm{Fe}_{2.23} \mathrm{~N}(120 \mathrm{~nm}) / \epsilon-{ }^{57} \mathrm{Fe}_{2.23}{ }^{15} \mathrm{~N}(10 \mathrm{~nm}) / \epsilon-\mathrm{Fe}_{2.23} \mathrm{~N}(120 \mathrm{~nm})$. More details about the deposition process are given in Ref. 30. The concentration depth profile was measured with a CAMECA-IMS5 F secondary ion mass spectrometer. The primary ions used for sputtering were $\mathrm{Cs}^{+}$ions of $4 \mathrm{keV}$ energy, and the ion current was about $30 \mathrm{nA}$. The secondary ions were detected by a double-focusing magnetic mass spectrometer. The obtained depth profiles were corrected for irradiation broadening following a procedure described in Refs. 15 and 30. The depth profiles of ${ }^{15} \mathrm{~N}$ and ${ }^{57} \mathrm{Fe}$ are given in Fig. 6 for the pristine samples and for samples after annealing at $448 \mathrm{~K}$ for $520 \mathrm{~min}$ and at $498 \mathrm{~K}$ for $300 \mathrm{~min}$. The annealing times were sufficient to achieve a structurally relaxed state of the samples. It can clearly be observed from Fig. 6 that the diffusion-mediated broadening of the ${ }^{57} \mathrm{Fe}$ profile is significantly larger than that of the ${ }^{15} \mathrm{~N}$ profiles, indicating that iron diffuses faster than nitrogen in this system.
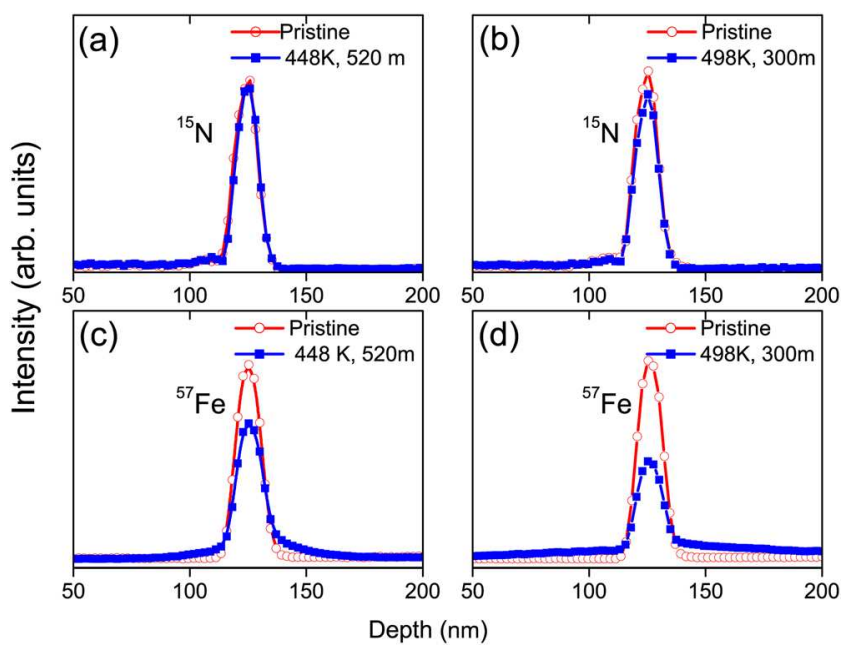

FIG. 6. (Color online) Diffusion broadening of the SIMS depth profile of ${ }^{57} \mathrm{Fe}$ and ${ }^{15} \mathrm{~N}$ in an $\epsilon-\mathrm{Fe}_{2.23} \mathrm{~N}(120 \mathrm{~nm}) / \epsilon-{ }^{57} \mathrm{Fe}_{2.23}{ }^{15} \mathrm{~N}(10 \mathrm{~nm}) / \epsilon-\mathrm{Fe}_{2.23} \mathrm{~N}(120$ $\mathrm{nm}$ ) trilayer sample after annealing at $448 \mathrm{~K}$ (a),(c) and $498 \mathrm{~K}$ (b),(d). 
In the present case, the thin film solution to Fick's law can be applied and the tracer concentration $c(x, t)$ of ${ }^{57} \mathrm{Fe}$ or ${ }^{15} \mathrm{~N}$ as a function of the penetration depth $x$ is given by ${ }^{43}$

$$
c(x, t)=\text { const } \exp \left(\frac{-x^{2}}{4 D t}\right),
$$

where $t$ is the time for annealing and $D$ is the diffusion coefficient. Accordingly, the profiles were fitted to a Gaussian distribution, and the time averaged diffusion coefficients were calculated using the following equation: ${ }^{44}$

$$
\langle D\rangle=\frac{\sigma_{t}^{2}-\sigma_{0}^{2}}{2 t},
$$

where $\langle D\rangle$ is the time averaged diffusivity, $\sigma_{t}$ is the standard deviation of the Gaussian depth profile obtained after an annealing time $t$, and $\sigma_{0}$ is the standard deviation of the asdeposited sample $(t=0)$. In Fig. 6, there is no broadening in the ${ }^{15} \mathrm{~N}$ depth profile that can be observed at an annealing temperature of $448 \mathrm{~K}$, whereas the depth profile of ${ }^{57} \mathrm{Fe}$ broadens. This indicates that no diffusion of ${ }^{15} \mathrm{~N}$ can be measured due to the limited depth resolution of SIMS. However, at 498 there is marginal broadening of ${ }^{15} \mathrm{~N}$ and significant broadening of ${ }^{57} \mathrm{Fe}$ depth profiles, and the measured diffusivity is plotted in Fig. 5(a). As can be seen, the values of diffusivity match well with those obtained with neutrons. This confirms that iron diffusion is faster than that of nitrogen.

In the literature it can be seen that the atomic size dependency (i.e., smaller atoms diffuse faster) is observed in metal-metal and metal-metalloid alloys. ${ }^{37,45}$ However, in the case of phosphorus self-diffusion in $\mathrm{Fe}_{40} \mathrm{Ni}_{40} \mathrm{P}_{14} \mathrm{~B}_{6}$ and in $\mathrm{Pd}_{43} \mathrm{Cu}_{27} \mathrm{Ni}_{10} \mathrm{P}_{20}$ metallic glass, the diffusion coefficient of $\mathrm{P}$ was found to be smaller than those of $\mathrm{Fe}$ and $\mathrm{Cu}^{46,47}$ It was suggested that the local chemical interactions around $\mathrm{P}$ (strong covalent bonds) are more important for the diffusion than the atomic size dependence of constituent elements in the alloy. In the periodic table, $\mathrm{N}$ and $\mathrm{P}$ are in the same group (VB), and the anomaly observed for P self-diffusion can be extended to $\mathrm{N}$ self-diffusion in nonmagnetic $\mathrm{Fe}-\mathrm{N}$ phases. However, as the temperature increased we observed that the difference between $\mathrm{Fe}$ and $\mathrm{N}$ diffusivity became small. Here it may be noted that by using neutron reflectivity, we could measure N self-diffusion at temperatures as low as $373 \mathrm{~K}$, and at this temperature the nitrogen diffusivity for sample $A 2$ was $1.8( \pm 2) \times 10^{-24} \mathrm{~m}^{2} \mathrm{~s}^{-1}$ in the relaxed state. Measurement of such a small diffusivity is not possible with any other technique.

It is known that a correlation exists between $\ln D_{0}$ and $E$ that is followed in all classes of materials and which indicates the involved diffusion mechanism. ${ }^{37}$ This correlation is known as the isokinetic relation and is given by ${ }^{48}$

$$
\ln D_{0}=\ln C 1+\frac{E}{C 2}
$$

where $C 1$ and $C 2$ are constants. When we compare our data with those available in the literature for crystalline and amorphous alloys, we find that our data closely follow the

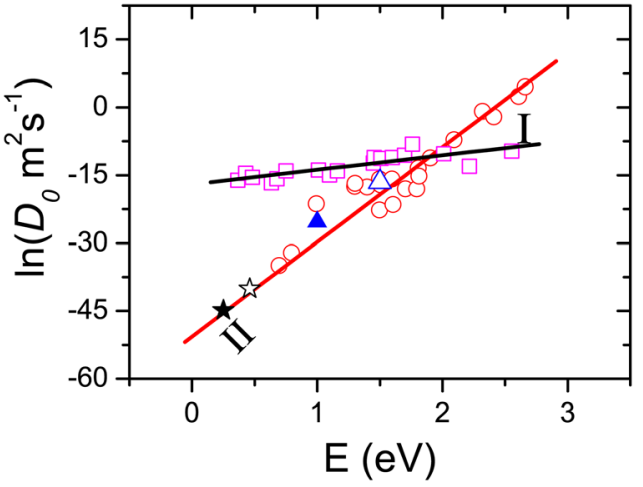

FIG. 7. (Color online) The correlation between $\ln D_{0}$ and $\mathrm{E}$ for crystalline (line I) and amorphous (line II) alloys (Ref. 37). The solid star represents data for sample $A 1$, the open star is for $A 2$, the solid triangle is for sample $B 1$, and the open triangle is for sample $B 2$, obtained in the present work.

correlation for amorphous alloys. Figure 7 compares our data with the $\ln D_{0}-E$ correlation for crystalline samples (line I) and amorphous alloys (line II) obtained in the literature. ${ }^{37}$ It may be noted that this correlation has a universal character, as it was found to be valid in crystalline and amorphous alloys. Although the samples in the present case are nanocrystalline thin films, it is interesting to see that they follow the correlation for amorphous alloys. Following Zener's theory of pre-exponential factors as discussed by Shewmon, ${ }^{43}$ the pre-exponential factor $\left(D_{0}\right)$ can be expressed as

$$
\ln D_{0}=\ln \left(g a^{2} f \nu_{0}\right)+\frac{\Delta S}{k_{B}},
$$

where $g$ is a geometry factor, $a$ is the effective jump distance, $\nu_{0}$ is the effective jump attempt frequency, $f$ is a correlation factor, and $\Delta S$ the entropy for diffusion. Using Eq. (6) we fitted a straight line to the data given in Fig. 7, which yields the values of constants $C 1$ and $C 2$. The obtained values of $C 1$ and $C 2$ are $(9 \pm 5) \times 10^{-23} \mathrm{~m}^{2} \mathrm{~s}^{-1}$ and $0.047 \pm 0.01 \mathrm{eV}$, respectively. It may be noted that the values of these constants differ significantly between crystalline and amorphous alloys. For crystalline alloys, constants $C 1$ and $C 2$ are typically $10^{-7} \mathrm{~m}^{2} \mathrm{~s}^{-1}$ and $0.4 \mathrm{eV}$, whereas in amorphous alloys they are on the order of $10^{-20} \mathrm{~m}^{2} \mathrm{~s}^{-1}$ and $0.05 \mathrm{eV}$. Clearly the values obtained in the present case match well with amorphous alloys.

Further, by using Eq. (7), we can calculate the values of $\Delta S$ for $\mathrm{Fe}$ and $\mathrm{N}$ diffusion, which are given in Table I. It may be noted that the value of the entropy $\Delta S$ corresponds to the number of atoms participating in the diffusion process. In crystalline solids, the values of $\Delta S$ are small ( $\sim 3$ to $5 k_{\mathrm{B}}$ ), whereas in amorphous alloys relatively large values $(\sim 19$ to $56 k_{\mathrm{B}}$ ) are obtained. ${ }^{37}$ In our case we find that the values of $\Delta S$ for $\mathrm{N}$ self-diffusion are $19 k_{\mathrm{B}}$ (for sample $A 2$ ) and $28 k_{\mathrm{B}}$ (for sample $B 2$ ), in contrast to the values for Fe self-diffusion of $5 k_{\mathrm{B}}$ (for sample $A 1$ ) and $9 k_{\mathrm{B}}$ (for sample $B 1$ ). Clearly, a larger group of $\mathrm{N}$ atoms participates in the diffusion process as compared to Fe atoms, making $\mathrm{N}$ diffusion slower than that of Fe.

Although the samples prepared in the present case are nanocrystalline thin films, their diffusion behavior is similar 
to that of amorphous alloys. It may be noted that the samples prepared in this work have very small grain sizes compared to the bulk material. With such a small grain size, it is expected that a large fraction consists of grains and grain boundary regions. In the literature it was found that the diffusion mechanism in thin film multilayers is similar to that in amorphous alloys, even though their structure is not amorphous. ${ }^{49,50}$ It was pointed out that an increased defect density in thin films might be responsible for such behavior. A small grain size and an increased defect density might present a microstructure analog for amorphous alloys. Therefore, the diffusion processes are basically controlled by the local microstructure. This explains the observed diffusivity in the present case.

\section{CONCLUSIONS}

In conclusion, we measured $\mathrm{Fe}$ and $\mathrm{N}$ self-diffusion in non-magnetic $\epsilon-\mathrm{Fe}_{2.23} \mathrm{~N}$ and $\gamma^{\prime \prime \prime}-\mathrm{FeN}$ compounds. The activation energies of $\mathrm{Fe}$ and $\mathrm{N}$ are higher in $\gamma^{\prime \prime \prime}-\mathrm{FeN}$ than in $\epsilon$ $\mathrm{Fe}_{2.23} \mathrm{~N}$. However, the diffusivity of $\mathrm{N}$ is smaller than that of $\mathrm{Fe}$ in both samples. The differences in $\mathrm{Fe}$ and $\mathrm{N}$ diffusivity cannot be understood in terms of the atomic size of $\mathrm{Fe}$ and $\mathrm{N}$. It was found that a significantly larger group of $\mathrm{N}$ atoms than of $\mathrm{Fe}$ atoms participates in the diffusion process, making $\mathrm{N}$ diffusion slower than that of $\mathrm{Fe}$.

\section{ACKNOWLEDGMENTS}

We acknowledge DST, Govt. of India, for providing financial support to carry out NR experiments under its scheme "Utilization of International Synchrotron Radiation and Neutron Scattering Facilities" through S. N. Bose National Centre for Basic Sciences. A part of this work was performed under the Indo Swiss Joint Research Programme funded by Grant No. INT/SWISS/JUAF(9)/2009 at the Swiss Spallation Neutron Source, Paul Scherrer Institute, Villigen, Switzerland. We are thankful to Dr. S. Chakravarty for SIMS measurements and Dr. P. Chaddah for continuous support and encouragement.

${ }^{1}$ X. Wang, W. T. Zheng, H. Tian, S. S. Yu, and L. L. Wang, J. Magn. Magn. Mater. 283, 282 (2004).

${ }^{2}$ T. K. Kim and M. Takahashi, Appl. Phys. Lett. 20, 492 (1972).

${ }^{3}$ M. Komuro, Y. Kozono, M. Hanazono, and Y. Sugita, J. Appl. Phys. 67, 5126 (1990).

${ }^{4}$ C. Navío, J. Alvarez, M. J. Capitán, D. Ecija, J. M. Gallego, F. Yndurain, and R. Miranda, Phys. Rev. B 75, 125422 (2007).

${ }^{5}$ C. Navío, J. Alvarez, M. J. Capitan, J. Camarero, and R. Miranda, Appl. Phys. Lett. 94, 263112 (2009).

${ }^{6}$ C. Navio, J. Alvarez, M. J. Capitan, F. Yndurain, and R. Miranda, Phys. Rev. B 78, 155417 (2008).

${ }^{7}$ L. de Wit, T. Weber, J. S. Custer, and F. W. Saris, Phys. Rev. Lett. 72, 3835 (1994).

${ }^{8}$ J. M. Gallego, D. O. Boerma, R. Miranda, and F. Ynduráin, Phys. Rev. Lett. 95, 136102 (2005).

${ }^{9}$ A. Oueldennaoua, E. Bauer-Grosse, M. Foos, and C. Frantz, Scr. Metall. 19, 1503 (1985).

${ }^{10}$ H. Nakagawa, S. Nasu, H. Fujii, M. Takahashi, and F. Kanamaru, Hyperfine Interact. 69, 455 (1991).

${ }^{11}$ K. Suzuki, H. Morita, T. Kaneko, H. Yoshida, and H. Fujimori, J. Alloys Compd. 201, 11 (1993)
${ }^{12}$ P. Schaaf, C. Illgner, M. Niederdrenk, and K. P. Lieb, Hyperfine Interact. 95, 199 (1995).

${ }^{13}$ T. Hinomura and S. Nasu, Physica B 237-238, 557 (1997).

${ }^{14}$ L. Rissanen, M. Neubauer, K. P. Lieb, and P. Schaaf, J. Alloys Compd. 274, 74 (1998).

${ }^{15}$ M. Gupta, A. Gupta, S. Rajagopalan, and A. K. Tyagi, Phys. Rev. B 65, 214204 (2002).

${ }^{16}$ D. M. Borsa and D. O. Boerma, Hyperfine Interact. 151-152, 31 (2003).

${ }^{17}$ X. Wang, W. T. Zheng, H. W. Tian, S. S. Yu, W. Xu, S. H. Meng, X. D. He, J. C. Han, C. Q. Sun, and B. K. Tay, Appl. Surf. Sci. 220, 30 (2003).

${ }^{18}$ R. Gupta and M. Gupta, Phys. Rev. B 72, 024202 (2005).

${ }^{19}$ I. Jouanny, P. Weisbecker, V. Demange, M. Grafouté, O. P. Na, and E. Bauer-Grosse, Thin Solid Films 518, 1883 (2010).

${ }^{20}$ M. Gupta, A. Gupta, P. Bhattacharya, P. Misra, and L. M. Kukreja, J. Alloys Compd. 326, 265 (2001).

${ }^{21}$ C. Navío, M. J. Capitán, J. Álvarez, R. Miranda, and F. Yndurain, New J. Phys. 12, 073004 (2010).

${ }^{22}$ A. Filippetti and W. E. Pickett, Phys. Rev. B 59, 8397 (1999).

${ }^{23}$ Y. Kong, J. Phys. : Condens. Matter 12, 4161 (2000).

${ }^{24}$ J. M. Gallego, S. Y. Grachev, D. M. Borsa, D. O. Boerma, D. Écija, and R. Miranda, Phys. Rev. B 70, 115417 (2004).

${ }^{25}$ M. S. Miao, P. Lukashev, A. Herwadkar, and W. R. L. Lambrecht, Phys. Status Solidi C 2, 2516 (2005).

${ }^{26}$ W. Y. Ching, Y. N. Xu, and P. Rulis, Appl. Phys. Lett. 80, 2904 (2002).

${ }^{27}$ J. M. D. Coey and P. A. I. Smith, J. Magn. Magn. Mater. 200, 405 (1999).

${ }^{28}$ P. Schaaf, Prog. Mater. Sci. 47, 1 (2002).

${ }^{29}$ J. L. Menendez, G. Armelles, A. Cebollada, F. Briones, F. Peiro, F. Guell, A. Cornet, M. L. F. Gubieda, J. Gutierrez, and C. Meyer, J. Appl. Phys. 89, 6314 (2001).

${ }^{30}$ S. Chakravarty, M. Gupta, A. Gupta, S. Rajagopalan, A. Balamurugan, A. Tyagi, U. Deshpande, M. Horisberger, and T. Gutberlet, Acta Mater. 57, 1263 (2009)

${ }^{31}$ M. Gupta, A. Gupta, J. Stahn, M. Horisberger, T. Gutberlet, and P. Allenspach, Phys. Rev.B 70, 184206 (2004).

${ }^{32}$ M. Gupta, T. Gutberlet, J. Stahn, P. Keller, and D. Clemens, Pramana, J. Phys. 63, 57 (2004).

${ }^{33}$ R. Cubitt and G. Fragneto, Appl. Phys. A 74, 329 (2002).

${ }^{34}$ M. Gupta, A. Tayal, A. Gupta, V. R. Reddy, M. Horisberger, and J. Stahn, J. Alloys Compd. 509, 8283 (2011).

${ }^{35}$ C. Braun, PARRATT32-The Reflectivity Tool, HMI, Berlin, 1997-1999.

${ }^{36}$ L. G. Parratt, Phys. Rev. 95, 359 (1954).

${ }^{37}$ F. Faupel, W. Frank, M. P. Macht, H. Mehrer, K. Rätzke, H. Schober, S. K. Sharma, and H. Teichler, Rev. Mod. Phys. 75, 237 (2003).

${ }^{38}$ M. P. Rosenblum, F. Spaepen, and D. Turnbull, Appl. Phys. Lett. 37, 184 (1980).

${ }^{39}$ J. Speakman, P. Rose, J. Hunt, N. Cowlam, R. E. Somekh, and A. Greer, J. Magn. Magn. Mater. 156, 411 (1996).

${ }^{40}$ M. Rennhofer, B. Sepiol, M. Sladecek, D. Kmiec, S. Stankov, G. Vogl, M. Kozlowski, R. Kozubski, A. Vantomme, J. Meersschaut, R. Rüffer, and A. Gupta, Phys. Rev. B 74, 104301 (2006).

${ }^{41}$ H. Schmidt, M. Gupta, and M. Bruns, Phys. Rev. Lett. 96, 055901 (2006).

${ }^{42}$ F. Tessier, A. Navrotsky, R. Niewa, A. Leineweber, H. Jacobs, S. Kikkawa, M. Takahashi, F. Kanamaru, and F. J. DiSalvo, Solid State Sci. 2, 457 (2000).

${ }^{43}$ P. G. Shewmon, Diffusion in Solids (Mc Graw-Hill, New York, 1963).

${ }^{44}$ Y. Loirat, J. L. Boequet, and Y. Limoge, J. Non-Cryst. Solids 262, 252 (2000).

${ }^{45}$ R. W. Cahn, J. E. Evetts, J. Patterson, R. E. Somekh, and C. K. Jackson, J. Mater. Sci. 15, 702 (1980).

${ }^{46}$ Y. Yamazaki, T. Nihei, J. Koike, and T. Ohtsuki, Proceedings of First International Conference on Diffusion in Solids and Liquids 2005 (Centre for Mechanical Technology and Automation and Department of Mechanical Engineering, University of Aveiro, Portugal), Vol. 2, p. 831.

${ }^{47}$ P. Valenta, K. Maier, and H. K. K. Freitag, Phys. Status Solidi B 106, 129 (1981).

${ }^{48}$ W. Linert, Chem. Soc. Rev. 18, 477 (1989).

${ }^{49}$ H. Schmidt, G. Borchardt, M. Rudolphi, H. Baumann, and M. Bruns, Appl. Phys. Lett. 85, 582 (2004).

${ }^{50}$ W.-H. Wang, H. Y. Bai, M. Zhang, J. H. Zhao, X. Y. Zhang, and W. K. Wang, Phys. Rev. B 59, 10811 (1999). 